\title{
Validation and comparison of 2D and 3D numerical simulations of flow in simplex nozzles
}

\author{
Mustafa Bal' ${ }^{* 1}$, Gökhan Kayansalçik², Özgür Ertunç ${ }^{2}$, Yakup Erhan Böke ${ }^{3}$ \\ ${ }^{1}$ Mechanical Engineering, Istanbul Technical University, Istanbul, Turkey \\ ${ }^{2}$ Mechanical Engineering, Özyeğin University, Istanbul, Turkey \\ ${ }^{3}$ Mechanical Engineering, Istanbul Technical University, Istanbul, Turkey
}

\begin{abstract}
Numerical simulations of pressure swirl atomizers are computationally expensive due to transient and multiphase flow behavior. In this study, 2D and 3D VOF simulations are performed for a geomerty which has high swirl chamber length-to-diameter ratio of 1.33. discharge coefficient (CD) and spray angle values are compared to the experimental data. Moreover, a benchmark study is conducted between 2D and 3D methods in terms of accuracy, computational cost and flow variables such as orifice exit axial and tangential velocity. The simulations are performed using a hybrid RANS-LES approach, IDDES model. It is observed that $2 \mathrm{D}$ simulation has lower accuracy in the validation parameters such as discharge coefficient and spray angle as compared to the 3D simulation. The main reason for $2 \mathrm{D}$ simulation inaccuracy might be the tangential port inlet effects and wrong estimation of the loss of swirl inside the swirl chamber. On the other hand, 2D simulations have approximately 1000 times lower computational cost than 3D simulations.
\end{abstract}

\section{Keywords}

VOF, pressure-swirl, simplex, CFD.

\section{Introduction}

Pressure swirl atomizers (PSA) are used to generate small liquid particles by ejecting the bulk liquid through a small exit orifice. Swirl motion is generally obtained by tangential inlet ports and converted into radial momentum after exiting the nozzle. In this way, higher spray angles are achieved compared to plain-orifice nozzles [1]. Pressure drop and spray angle of the atomizer highly depend on the design of the internal geometrical features [2,3]. Eulerian multiphase flow simulations are conducted to estimate the pressure drop and spray angle for a certain mass flow rate. This helps the designer to obtain a nozzle at a specific discharge coefficient (CD-Eq.1) and spray angle. However, if the estimations are far away from the experimental values designs can be misleading or number of design iterations might increase. CD and spray angle of the nozzles can be estimated using 2D axisymmetric swirl approach or full sector 3D simulations. Transient simulations are generally preferred due to unstable flow behavior. 2D method is applied due to its significantly lower computational cost compared to 3D method.

Various approaches have been used to model liquid-gas interface and turbulence in the flow field. One of the most common method is VOF method and it is applied by representing each cell by a volume fraction [4-7]. Volume fraction values are calculated via solving transport equations for the phases. Generally, either geometric reconstruction or compressive schemes such as modified HRIC (high resolution interface capturing) are used for volume fraction discretization [8,9]. Geometric reconstruction is generally preferred for sharper liquid-gas interface but with a higher computational cost. On the other hand, reasonably low diffusion at the phase interface can be obtained for a lower cost with modified HRIC scheme. 
In previous studies, turbulence modelling is mainly focused on laminar, RSM models and LES approaches. Eddy-viscosity models generally fail to predict to capture main flow characteristics such as CD and spray angle [10]. Laminar modelling is applied with the assumption of stabilization effect of streamline curvature inside the atomizer [5]. Moreover, three dimensional laminar simulations were conducted by Razeghi and Ertunç for the investigation of internal flow and initial phase of the atomization [7]. Ibrahim et. al. implemented the RSM model to capture highly anisotropic swirling flow inside the atomizer [11]. Hansen et. al. used LES and laminar models and compared the mean and fluctuating velocity components inside the nozzle [12].

In this study, a hybrid RANS-LES approach IDDES (Improved Delayed Detached Eddy Simulation) is used along with the VOF method. Experiments conducted for a PSA and CD and spray angle values are validated against the experimental data. Finally, 2D and 3D methods are compared in terms of accuracy in validation parameters and computational cost of the simulations.

\section{Material and Methods}

Plexi-glass nozzle designed for the experiments and simulations has $1.33 L_{S} / D_{S}$ ratio, and 0.5 $l_{o} / d_{o}$ ratio. Geometric parameters are defined in Fig. 1 and listed in Table 1.
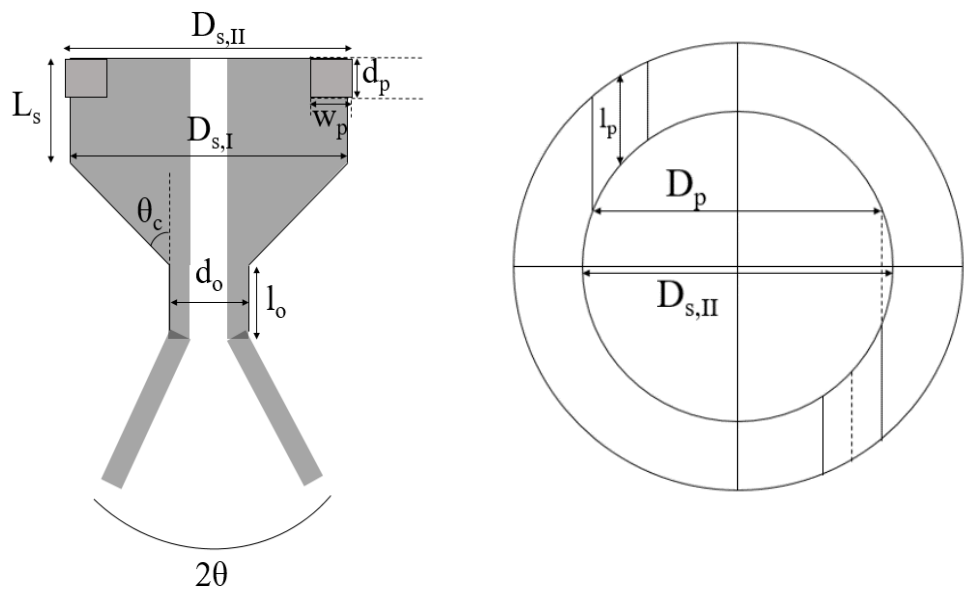

Figure 1. Nozzle geometric parameters specifications

Table 1. Nozzle geometric parameters

\begin{tabular}{|c|c|c|c|}
\hline Number of ports & 2 & $\begin{array}{c}\text { Inlet port outer } \\
\text { diameter, } D_{p}(\mathrm{~mm})\end{array}$ & 17.5 \\
\hline $\begin{array}{l}\text { Inlet port width, } w_{p} \\
(\mathrm{~mm})\end{array}$ & 4.5 & $\begin{array}{c}\text { Swirl chamber } \\
\text { diameter I, } D_{\mathrm{s}, \mathrm{I}}(\mathrm{mm})\end{array}$ & 17.5 \\
\hline $\begin{array}{l}\text { Inlet port depth, } d_{p} \\
(\mathrm{~mm})\end{array}$ & 4.5 & $\begin{array}{c}\text { Swirl chamber } \\
\text { diameter II, } D_{\mathrm{s}, I I}(\mathrm{~mm})\end{array}$ & 18.5 \\
\hline $\begin{array}{l}\text { Orifice diameter, } \mathrm{d}_{\mathrm{o}} \\
(\mathrm{mm})\end{array}$ & 5 & $\begin{array}{c}\text { Swirl chamber length, } \\
L_{s}(\mathrm{~mm})\end{array}$ & 23.3 \\
\hline Orifice length, $\mathrm{I}_{\mathrm{O}}(\mathrm{mm})$ & 2.5 & $\begin{array}{c}\text { Swirl chamber } \\
\text { contraction angle, } \theta_{\mathrm{c}} \\
\left({ }^{\circ}\right)\end{array}$ & 45 \\
\hline $\begin{array}{l}\text { Inlet port length, } I_{p} \\
(\mathrm{~mm})\end{array}$ & 6.75 & & \\
\hline
\end{tabular}


Mass flow is measured using ABB FEP311 electromagnetic flow meter and ABB 261 GS pressure transducer is used for pressure measurements. CD is calculated based on Eq. 1 and the uncertainty due to measurement and production errors is approximated as $\pm 2 \%$.

$$
C D=\frac{\dot{m}}{A_{o} \sqrt{2 \Delta P \rho_{\text {liq }}}}
$$

Ansys Fluent 18.2 is used for the simulations. Implicit VOF scheme is selected and global courant number limit is set to 1. CSF (Continuum Surface Force) model is preferred using a constant surface tension value of $0.072 \mathrm{~N} / \mathrm{m}$ for water [13]. For turbulence closure, IDDES model is used [14]. Bounded central differencing is applied for the discretization of momentum equations. Moreover, bounded second order implicit scheme is used for temporal discretization. Modified HRIC is preferred for volume fraction discretization.

For 2D and 3D simulations, velocity-inlet and pressure outlet boundary conditions are applied. Velocity components and corresponding inlet slot lengths are calculated for 2D simulations. The method used to calculate the radial and tangential velocities at the inlet is based on Ibrahim's study [11]. 2D axisymmetric solution includes the swirl motion whereas gradients in the circumferential direction are zero. In 3D simulations, axial velocity is set for the desired mass flow rate. Inlet fluctuations are defined using vortex method.

Grids are generated using Ansys Meshing 2020R1. Fully structured grids are used for 2D and 3D simulations. Grid specifications are based on Menter's study on hybrid RANS-LES best practices [15]. In Fig. 2, 2D the mesh is shown. The grid consists of approximately 30000 elements. Half orifice has 60 layers parallel to the axis. The mesh is generated so that $y+$ values at the orifice region are approximately 2-2.5.

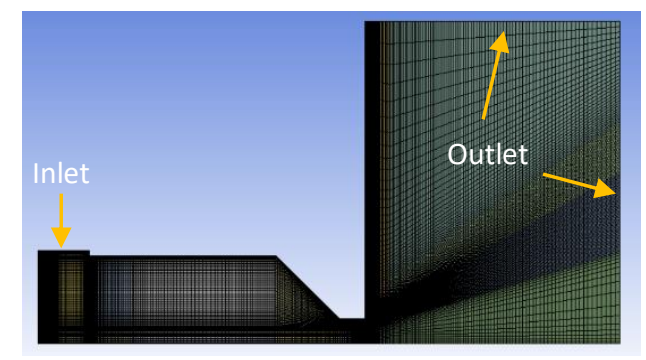

Fig. 2 2D structured grid

Baseline 3D mesh is generated based on orifice $y+$ values of 2-2.5, and 120 division in circumferential direction. Additionally, axial density is arranged based on achieving less than 5 aspect ratio in the free stream. 3D mesh structure is shown in Fig. 3.

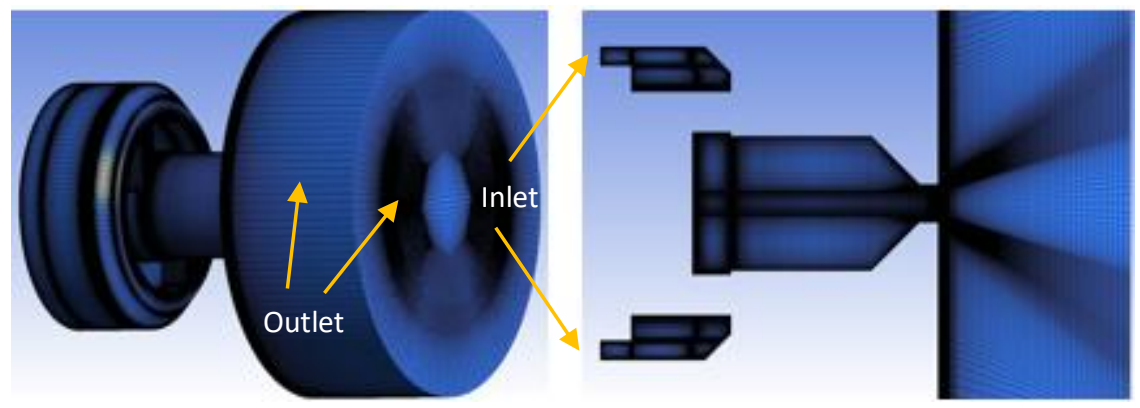

Figure 3. 3D structured grid 
Governing equations for the continuity, momentum and volume fraction are shown in Eq. 2-9 $[9,13,16-17]$.

$$
\begin{aligned}
& \frac{\partial}{\partial t} \int_{V} \rho d V+\oint \rho \boldsymbol{U} \cdot \boldsymbol{n} d A=0 \\
& \frac{\partial}{\partial t} \int_{V} \rho \boldsymbol{U} d V+\oint \rho \boldsymbol{U} \otimes \boldsymbol{U} \cdot \boldsymbol{n} d A=-\oint P \boldsymbol{n} d A+\oint \mu \nabla \boldsymbol{U} \cdot \boldsymbol{n} d A+\int_{V} f_{S} d V+\int_{V} \rho \boldsymbol{g} d V \quad \text { Eq. (3) } \\
& f_{s}=\sigma_{i j} \frac{\rho \kappa_{i} \nabla \alpha_{i}}{\frac{1}{2}\left(\rho_{i}+\rho_{j}\right)} \\
& \frac{\partial}{\partial t} \int_{V} \alpha_{i} d V+\oint \alpha_{i} \boldsymbol{U} \cdot \boldsymbol{n} d A=0 \\
& \rho=\sum_{p=1}^{n} \alpha_{i} \rho_{i} \\
& \mu=\sum_{p=1}^{n} \alpha_{i} \mu_{i}
\end{aligned}
$$

Adopting the Reynolds decomposition for the velocity and pressure, as $\boldsymbol{U}(t)=\overline{\boldsymbol{U}}+\boldsymbol{u}(t)$ and $P(t)=\bar{P}+p(t)$ where $=\left[\begin{array}{c}U_{x} \\ U_{y} \\ U_{z}\end{array}\right]$, the RANS equations reads;

$$
\begin{gathered}
\oint \rho \bar{U} \cdot \boldsymbol{n} d A=0 \\
\frac{\partial}{\partial t} \int_{V} \rho \overline{\boldsymbol{U}} d V+\oint \rho \overline{\boldsymbol{U}} \otimes \overline{\boldsymbol{U}} \cdot \boldsymbol{n} d A=\oint \bar{P} \boldsymbol{n} d A+\oint \mu(\nabla \overline{\boldsymbol{U}}-(\overline{\boldsymbol{u} \otimes \boldsymbol{u}})) \cdot \boldsymbol{n} d A+\int_{V} \overline{f_{S}} d V
\end{gathered}
$$

where over-bar symbol denotes time averaged values and $\overline{\boldsymbol{u} \otimes \boldsymbol{u}}$ represents Reynolds stresses.

Turbulent diffusion and dissipation are solved by using shield functions which utilize different length and time scales for RANS and LES portions of the simulation. Details for the formulations of turbulence equations and DES approaches can be found in the literature [14].

Grid sensitivity for 2D simulations is conducted using three different sizes, 15, 30 and 56 thousand cells. At every refinement step, number of divisions are increased by a factor of 1.2 in the entire domain. CD values are calculated as 0.412 and 0.411 for 30 thousand and 56 thousand cells respectively. Moreover, spray angles are measured as 64.8 and $64.9^{\circ}$. Hence 30 thousand cells are selected for 2D simulations. CD and spray angle results for $2 \mathrm{D}$ grid sensitivity are show in Fig. 4 and Fig 5. 

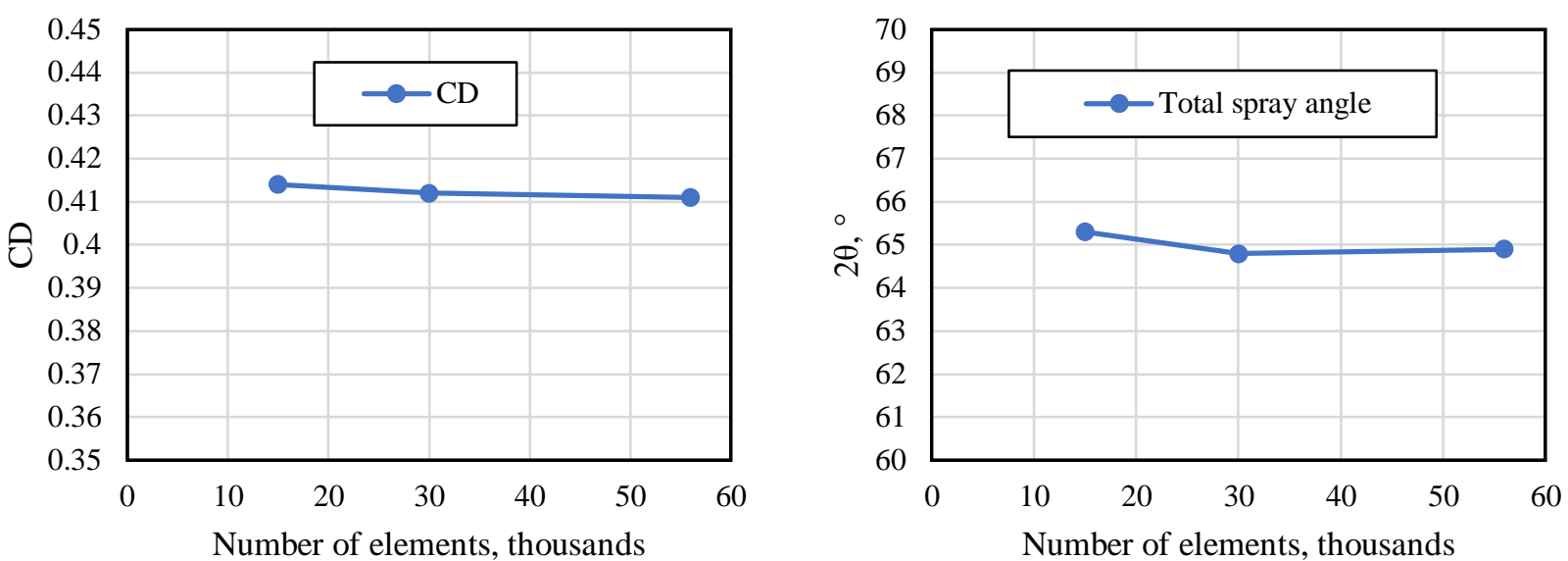

Figure 4. Grid sensitivity of $C D$ and $2 \theta$ for $2 D$ simulations at $80 \mathrm{~g} / \mathrm{s}$

For 3D simulations, 3.80, 6.57 and 11.53 million hexahedral elements are used for grid sensitivity. Results for different sizes of grid are shown in Fig. 5. Moreover, spray angle measurement is shown for 6.57 million grid in Fig. 6 .
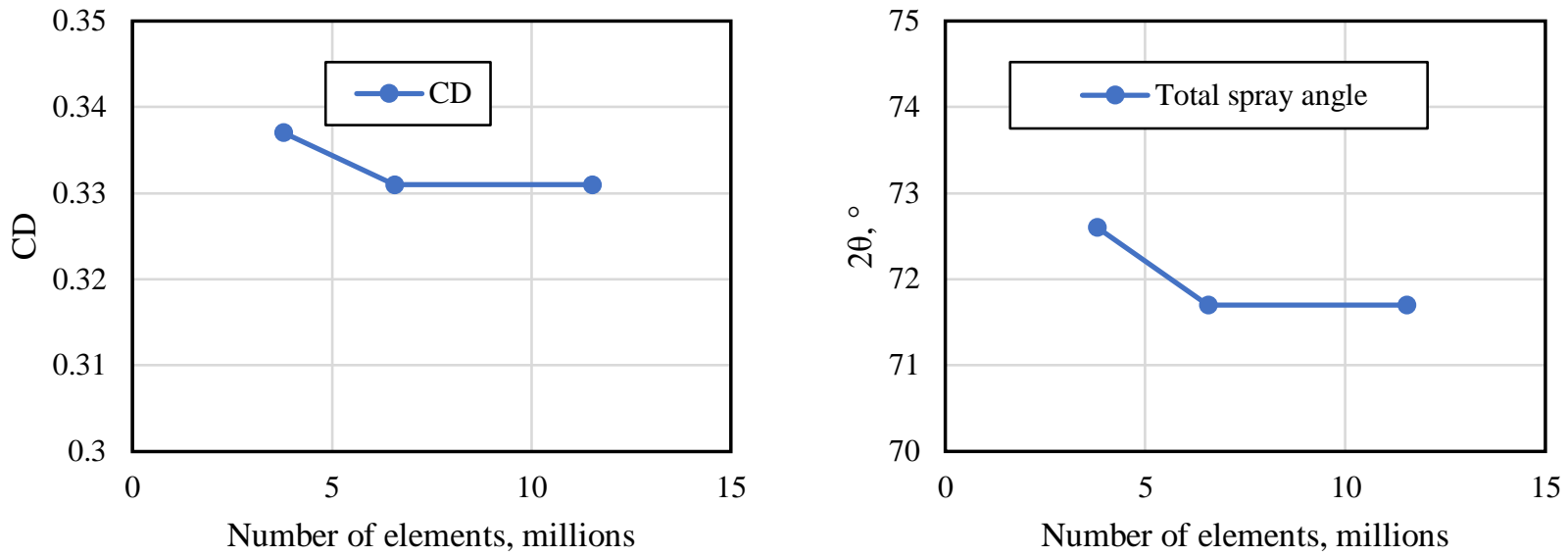

Fig. 5 Grid sensitivity analysis for CD and total spray angle at $80 \mathrm{~g} / \mathrm{s}$

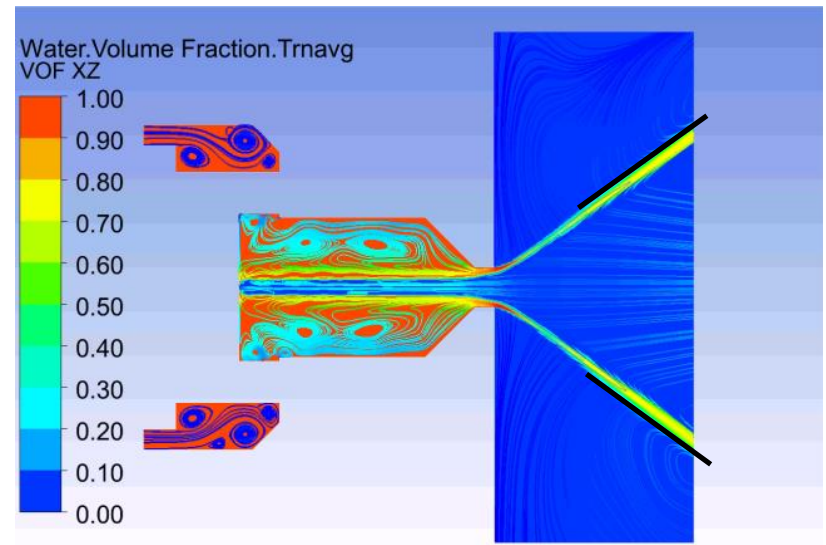

Fig. 6 Spray angle measurement for 6.57 million grid at $80 \mathrm{~g} / \mathrm{s}$

CD values for 6.57 and 11.53 million grids are calculated as 0.331 . Moreover spray angle is measured the same for the two meshes as $71.7^{\circ}$. Therefore, 6.57 million cells grids size is selected for 3D simulations. 


\section{Results and Discussion}

Transient simulations are conducted for $2 \mathrm{D}$ and $3 \mathrm{D}$ simulations using maximum CFL number 1 which corresponds to a time step of $5 e-7$ to $2 e-6$ seconds for different grid sizes. Simulations are run for approximately 0.25 seconds which accounts for 3 turnover time of the nozzle. In the 2D simulation, time averaged VOF contour and tangential velocity behaviour shown in Fig. 8 seem appropriate for the flow physics of a hollow cone pressure swirl atomizer.
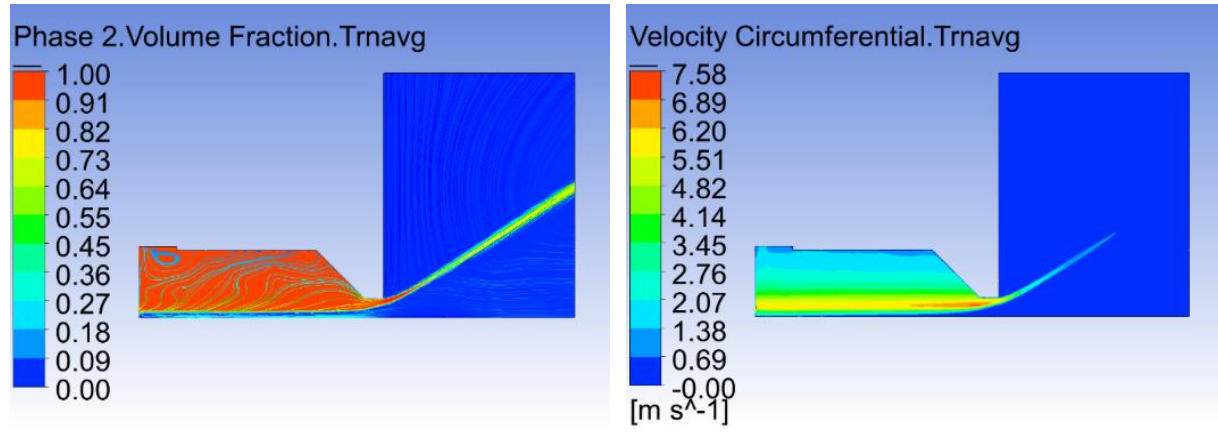

Fig 7. 2D time averaged VOF contour along with velocity streamlines (left) and tangential velocity contour (right) at $80 \mathrm{~g} / \mathrm{s}$

Secondary vortices are not observed in the swirl chamber except for a small vortex at the inlet of the swirl chamber. Tangential velocity contour is in line with Rankine vortex behavior. CD is calculated as 0.412 and total spray angle is measured as $64.8^{\circ}$. In Table 2, velocity components calculated at the orifice exit are shown. It is seen that tangential velocity is significantly lower than axial velocity which results in low spray angle.

2D simulations are conducted with a single core CPU. Total duration of the simulation including the statistical averaging is measured as 26 hours. Therefore, the computational cost of the $2 \mathrm{D}$ simulation becomes 26 core-hours.

Additional Taylor vortices are observed in the swirl chamber for 3D simulations as shown in Fig. 8. On the other hand, tangential velocity behavior is similar to the $2 \mathrm{D}$ analysis as it increases towards the center of the nozzle. CD is calculated as 0.332 and total spray angle is measured as $71.7^{\circ}$. Velocity components at the orifice exit for 3D simulation are shown in Table 5 . Orifice exit velocity magnitude is $22.8 \%$ higher in $3 \mathrm{D}$ simulations.

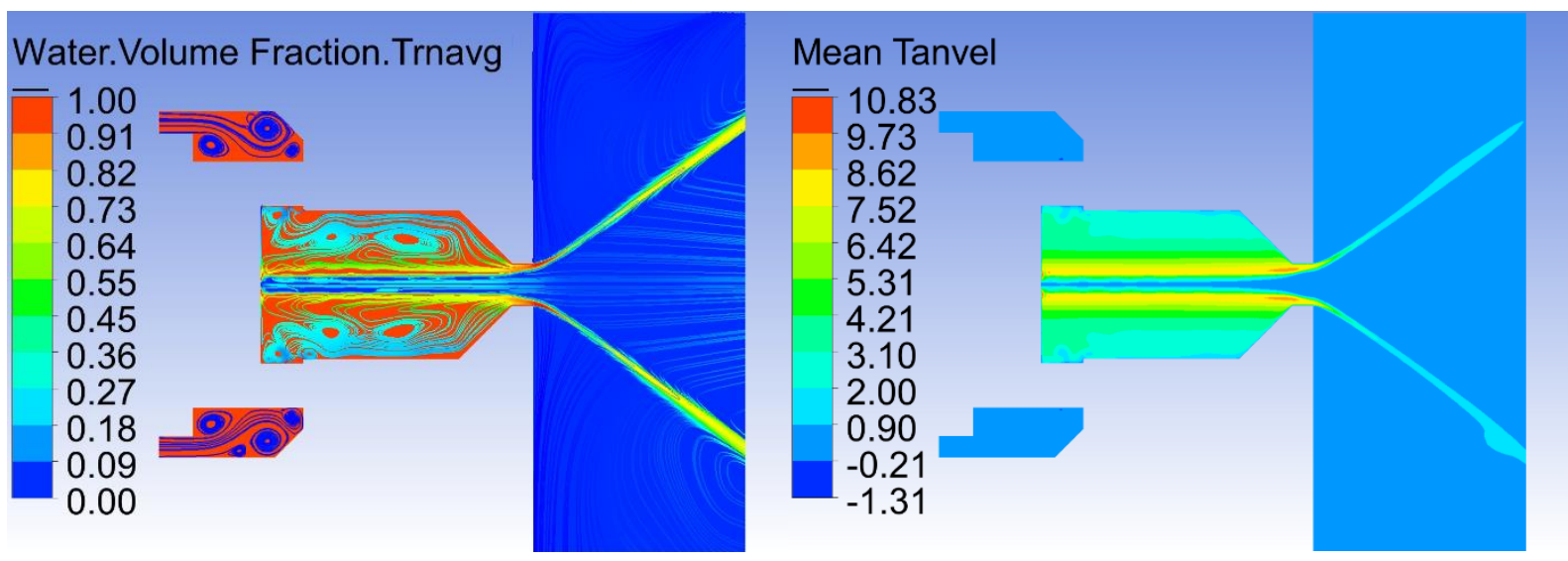

Fig. 8 3D time averaged VOF contour along with velocity streamlines (left) and tangential velocity contour (right) at $80 \mathrm{~g} / \mathrm{s}$ 
Table 2. 2D and 3D Simulations Orifice Exit Velocity Components at $80 \mathrm{~g} / \mathrm{s}$

\begin{tabular}{cccc}
\hline \hline Simulation Type & $\begin{array}{c}\text { Water Orifice Exit Axial } \\
\text { Velocity }(\mathrm{m} / \mathrm{s})\end{array}$ & $\begin{array}{c}\text { Water Orifice Exit } \\
\text { Tangential Velocity }(\mathrm{m} / \mathrm{s})\end{array}$ & $\begin{array}{c}\text { Water Orifice Exit Velocity } \\
\text { Magnitude }(\mathrm{m} / \mathrm{s})\end{array}$ \\
\hline 2D & 7.30 & 4.88 & 8.89 \\
\hline 3D & 8.56 & 6.57 & 10.92 \\
\hline \hline
\end{tabular}

3D simulations are conducted using 8 node HPC cluster with 240 cores. Total duration is measured as 103 hours. Hence, the computational cost becomes 24720 core-hours. The increase in computational cost basically comes from the number of elements used in the 3D domain.

Experiments are conducted for the plexi-glass nozzle using water at $20^{\circ} \mathrm{C}$ and flow rate and pressure measurements are taken. Tangential port inlet Reynolds number is calculated as 8905 for $80 \mathrm{~g} / \mathrm{s}$ flow rate and 4453 for $40 \mathrm{~g} / \mathrm{s}$ flow rate. Moreover, 100 images are merged to calculate the time averaged spray angle as shown in Fig. 9.

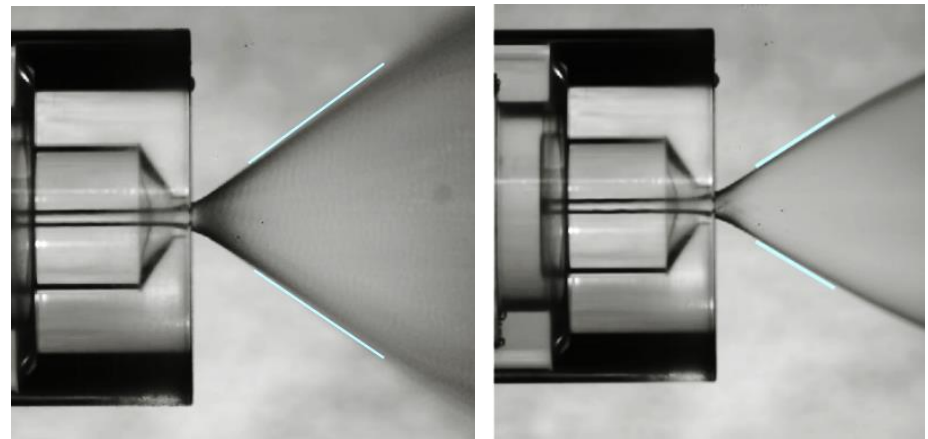

Figure 9. High speed camera recording of the nozzle at $80 \mathrm{~g} / \mathrm{s}$ (left) and $40 \mathrm{~g} / \mathrm{s}$ (right).

The results for CD, total spray angle and film thickness are compared in Table 3.

Table 3. Comparison of 2D-3D simulation results and experimental data

\begin{tabular}{c|c|ccccc}
\hline \hline \multirow{2}{*}{$\begin{array}{c}\text { Flow rate } \\
(\mathrm{g} / \mathrm{s})\end{array}$} & Simulation Type & $\begin{array}{c}\text { Discharge } \\
\text { coefficient } \\
(\mathrm{CD})\end{array}$ & $\begin{array}{c}\text { Total spray } \\
\text { angle }(2 \theta)\end{array}$ & $\begin{array}{c}\text { Film thickness } \\
(\mathrm{mm})\end{array}$ & $\begin{array}{c}\text { Computational } \\
\text { cost (core- } \\
\text { hours) }\end{array}$ & $\begin{array}{c}\text { Number of } \\
\text { elements } \\
\text { (millions) }\end{array}$ \\
\hline \multirow{3}{*}{$80 \mathrm{~g} / \mathrm{s}$} & Experimental & 0.336 & 72.5 & 0.71 & - & - \\
\cline { 2 - 7 } & 2D axisymmetric & 0.412 & 64.8 & 0.81 & 26 & 0.03 \\
\cline { 2 - 7 } & Full sector 3D & 0.331 & 71.7 & 0.70 & 24720 & 6.57 \\
\hline \multirow{3}{*}{$40 \mathrm{~g} / \mathrm{s}$} & Experimental & 0.352 & 63.2 & 0.87 & - & 0.03 \\
\cline { 2 - 7 } & 2D axisymmetric & 0.426 & 54.8 & 0.84 & 26 & 6.57 \\
\cline { 2 - 7 } & Full sector 3D & 0.340 & 67.9 & 0.75 & 24720 & \\
\hline \hline
\end{tabular}

Generally, accuracies in the 3D simulations are high for CD and spray angle. Maximum CD error is calculated as $3.5 \%$ and spray angle error is calculated as $4.7^{\circ}$ at $40 \mathrm{~g} / \mathrm{s}$ flow rate. On the other hand, maximum CD error for the 2D simulations reach up to $22.6 \%$ and maximum spray angle error is calculated as $7.7^{\circ}$ at $80 \mathrm{~g} / \mathrm{s}$ flow rate. When the flow rate is decreased from $80 \mathrm{~g} / \mathrm{s}$ to $40 \mathrm{~g} / \mathrm{s}, C D$ and film thickness increases slightly in the experiments. This behaviour is captured with 2D and 3D simulations. However, there is an overshoot of CD and film thickness in 2D simulation results. Accordingly, orifice exit velocity components are lower in 2D simulations as shown in Table 2. Additionally, spray angles are lower than the experimental data and 3D simulations. The main reason for poor estimation of $C D$ in $2 D$ simulations might be related with the lower level of swirl calculated inside the nozzle than that in 3D simulations. Since swirl is directly related with the film thickness, axial velocity at the orifice exit is also affected by the swirl level. 


\section{Conclusions}

A generic hollow-cone simplex nozzle is tested and flow simulations are conducted in 2D and 3D computational domain. Although the computational cost for 2D method is approximately 1000 times lower than 3D method, CD estimation error at $80 \mathrm{~g} / \mathrm{s}$ are calculated as $22.6 \%$ higher than the experimental data. On the other hand, CD and spray angle predictions with 3D simulations are quite close to the experimental data. For this type of geometry and similar inlet Re numbers, 3D simulations could be very useful to obtain more precise CD and spray angle values. If $2 \mathrm{D}$ simulations have to be used, the effect of the inlet boundary condition on the generated swirl and viscous dissipation in the nozzle should be investigated in detail.

\section{Acknowledgments}

This study was carried out in the framework of a $\mathrm{PhD}$ thesis. Computational resources were supplied from Istanbul Technical University through BAP project ID number 42673 and National Center for High Performance Computing (UHEM). Moreover, the authors gratefully acknowledge the Scientific and Technological Research Council of Turkey (TÜBITAK) and TEI for providing financial support to this research with the $118 \mathrm{C} 053$ project. Additionally, we would like to thank Hakan Çiçek for the support he has given at the nozzle modelling process.

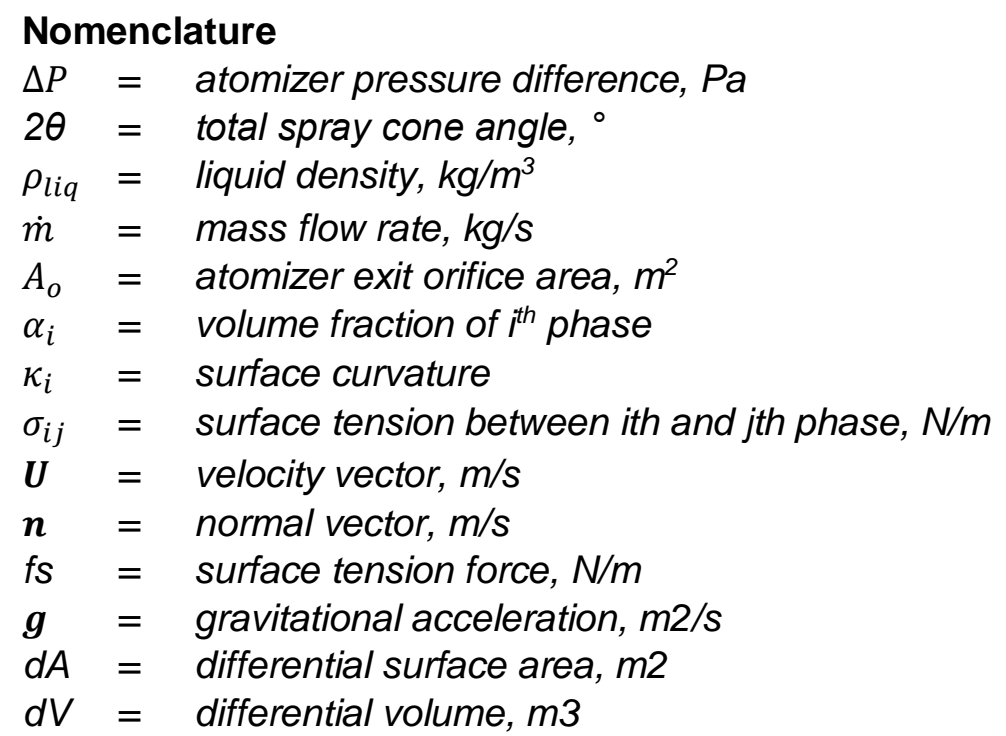

\section{References}

[1] Lefebvre, A. H. and McDonell, V. G., Atomization and Sprays, pp. 1-284, 2017.

[2] Bayvel, L., Orzechowski, Z., Liquid Atomization, 1st ed., Taylor and Francis, Bosa Roca, pp. 1-35; 159-235, 1993.

[3] Khavkin, Y. Theory and Practice of Swirl Atomizers, 1st ed., Taylor and Francis, Bosa Roca, pp. 1-178, 2004.

[4] Ergen, T., and Tunçer, O. "Basınç Girdaplı Bir Püskürteçte Damlacık Boyut Dağılımı ve Hava Çekirdeği Kararsızlığının İncelenmesi," 19th National Mechanical Congress, Karadeniz Technical Univ., Trabzon, pp. 464-471, 2015.

[5] Dash, S. K., Halder, M. R., Peric, M., and Som, S. K., "Formation of Air Core in Nozzles with Tangential Entry," Journal of Fluids Engineering, Transactions of the ASME, vol. 123, No. 4, pp. 829-835, 2001.

[6] Agarwal, P., Sethi, V., Gauthier, P. Q., Sun, X., and Liu, Y., "Preliminary CFD Study on the Effect of Fuel Injector Coking on Fuel Spray Characteristics," Proceedings of the ASME 2017 Gas Turbine India Conference, GTINDIA 2017, vol. 1, Bangalore, India, pp. 1-10, 2017, DOI: 10.1115/GTINDIA2017-4838. 
[7] Razeghi, A. and Ertunç, Ö., Numerical Investigation of Multiphase Flow inside a Pressure Swirl Atomizer at the Initial Stage of Injection, Atomization and Sprays, vol. 28, no. 5, pp. 41741, 2018. DOI: 10.1615/atomizspr.2018022872

[8] Mirjalili, B. S., Jain, S. S. and Dodd, M. S., Interface-Capturing Methods for Two-Phase Flows: An Overview and Recent Developments, Center for Turbulence Research: Annual Research Briefs, vol. 1, pp. 117-35, 2017. DOI: http://dx.doi.org/10.1080/10304312.2017.1409340

[9] Muzaferija, S., Peric, M., "Computation of Free Surface Flow Using Interface-Tracking and Interface-Capturing Methods," Nonlinear Water Wave Interaction, edited by O. Mahrenholtz and M. Markiewicz, WIT Press, Southampton, pp. 59-100, 1999.

[10] Baharanchi, A. A., Gokaltun, S., and Eshraghi, S., "A Numerical Approach for the Simulation of Internal Nozzle Flow in a Pressure Swirl Atomizer Using Different Turbulent Models and towards an Effective Inlet Weber Number," Proceedings of the ASME 2013 International Mechanical Engineering Congress and Exposition, Proceedings (IMECE), vol. 7A, San Diego, California, pp. 1-9, 2013. DOI: 10.1115/IMECE2013-65627

[11] Ibrahim, A. A. and Jog, M. A., Nonlinear Breakup Model for a Liquid Sheet Emanating from a Pressure-Swirl Atomizer, Journal of Engineering for Gas Turbines and Power, vol. 129, no. 4, pp. 945-53, 2007. DOI: 10.1115/1.2747263

[12] Hansen, K. G., Madsen, J., Trinh, C. M., Ibsen, C. H., Solberg, T., and Hjertager, B. H., Computational and Experimental Study of the Internal Flow in a Scaled Pressure Swirl Atomizer, "ILASS Europe, Zaragoza, 2002, pp. 1-6.

[13] Brackbill, J. U., Kothe, D. B., and Zemach, C., "A Continuum Method for Modeling Surface Tension," Journal of Computational Physics, vol. 100, No. 2, pp. 335-354, 1992. DOI: 10.1016/0021-9991(92)90240-Y

[14] Gritskevich M. S., Garbaruk A. V., Schutze J., Menter F. R., "Development of DDES and IDDES Formulations for the k- $\omega$ Shear Stress Transport Model," Flow, Turbulence and Combustion, vol. 88, No. 3, pp. 431-449, 2012. DOI: 10.1007/s10494-011-9378-4

[15] F. R. Menter. Best Practice: Scale-Resolving Simulation in ANSYS CFD, 2012.

[16] Ferziger, J. H. and Perić, M., Computational Methods for Fluid Dynamics, 3rd ed., Berlin: Springer, pp. 4-9, 2002.

[17] Davidson, P. A., Turbulence: An Introduction for Scientists and Engineers, 2nd ed., Oxford: Oxford University Press, pp. 35-41; 108-119, 2015. 